ISSN (online): 2581-3048

\title{
Fire Fighting Robot
}

\author{
${ }^{1}$ Devendra Itole, ${ }^{2}$ Pratik Kumbhar, ${ }^{3}$ Chaitanya Kharche, ${ }^{4}$ Vaibhav Lonari \\ ${ }^{1}$ Asst. Prof., Electronics \& Telecommunication Engineering, All India Shri Shivaji Memorial Society Institute of Information \\ Technology, Pune, Maharashtra, India \\ ${ }^{2,3,4}$ Student, B.E. Electronics \& Telecommunication Engineering, All India Shri Shivaji Memorial Society Institute of Information \\ Technology, Pune, Maharashtra, India
}

\begin{abstract}
When the robot is moving on a surface if any fire accident occurs then the motor gets switched on which in turn switches on the water sprinkler (pump). The ESP8266 WiFi Module is a self-contained SOC with integrated TCP/IP protocol stack that can give any microcontroller access to your WiFi network. The ESP8266 is capable of either hosting an application or offloading all WiFi networking functions from another application processor. Each ESP8266 module comes pre-programmed with an AT command set firmware, meaning, you can simply hook this up to your Arduino device and get about as much WiFi-ability as a WiFi Shield offers (and that's just out of the box)! The ESP8266 module is an extremely cost effective board with a huge, and ever growing, community. This project uses 9V battery. This project is much useful for mines detection and surveillance applications. Robotics has gained popularity due to the advancement of many technologies of computing and nano technologies. So, we proposed to design something that can make humans life easier and comfortable. This project, which is o rendeavorto design a fire fighting robot. Comprises of a machine which not only has the basic features of the robot, but also has the ability to detect fire and extinguish it. The need of the hour is make a device which can detect fire, even if it is small and take the necessary action to put it off. Fire fighters are primarily tasked to handle fire incidents, but they are often exposed to higher risks when extinguishing fire, especially in hazardous environments such as in nuclear power plant, petroleum refineries and gas tanks.
\end{abstract}

Keywords: Fire, Fighting, Robot, Wi-Fi.

\section{INTRODUCTION}

Path Finder was sent to Mars in 1998. This was a great achievement which detected the secrets of "Mars". The robot is prototype for the "Path Finder". This robot is a IOT controlled robot. This can be moved forward and reverse direction using geared motors of 60RPM. Also this robot can take sharp turnings towards left and right directions. This project uses Pic as its controller. This Robot is used as a fire extinguisher i.e. it sprinkles the water on to the fire in case of fire accidents. A Robot is a mechatronics device which also includes resourcefulness or autonomy. A device with autonomy does its thing "on its own" with a human directly guiding it moment-by-moment. Some authors would contend that all mechatronic devices are robots, and that this book's restriction on robot entails only specialized software. Nowadays, machinery and robotic design become important in helping human.

This Fire Protection Robot was design to help people in any destructive burnt situation where this robot can extinguish burnt area immediately using autonomous system. This autonomous system will be designed using programming in PIC18F4550 and others additional circuit. In real life, destructive burnt area often happens without our realization. Therefore, this type of robot will require a high demands in the market because of its usefulness to the human as well as the environment transmit fire information to cell phone using GSM modern.

The objective of the project will be to design a SMS electronic Fire Protection Robot toolkit which can replace the traditional Fire Protection Robot. The toolkit send the fire and send SMS to owner of the house, The system is made 2 efficient by SIMs so that the SMS can be received by number of devices boards in a locality using techniques of time division multiple access. The AT commands are serially transferred to the modem. In return the modem transmits the stored message through the wireless link. The microcontroller validates and then perform specific task on the device.

\section{METHODOLOGY}

At the transmitting end using Mobile Phone, commands are sent to the receiver to control the movement of the robot either to move forward, backward and left or right etc. At the receiving end three motors are interfaced to the microcontroller where two of them are used for the movement of the vehicle and the remaining one to position the arm of the robot. The Bluetooth Transceiver acts as a remote control that has the advantage of adequate range, while microcontroller to drive DC motors via motor driver IC for necessary work. A water tank along with water pump is mounted on the robot body and its operation is carried out from the microcontroller 
ISSN (online): 2581-3048

output through appropriate signal from the transmitting end. The whole operation is controlled by a PIC microcontroller.

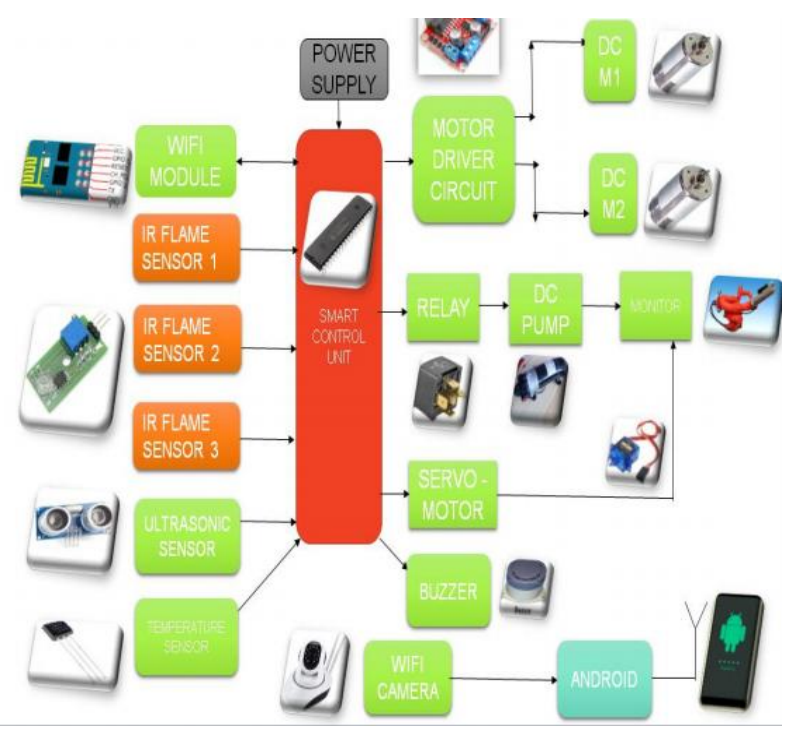

Figure 1: System Architecture

Microcontroller PIC18F4520: Features: 40-pin Low Power Microcontroller Flash Program Memory: 32 kbytes EEPROM Data Memory: 256 bytes SRAM Data Memory: 1536 bytes I/O Pins: 36 Timers: One 8-bit / Three 16-Bit A/D Converter: 10-bit Thirteen Channels PWM: 10-bit Two Modules Enhanced USART: Addressable with RS485, RS-232 and LIN Support MSSP: SPI and $\mathrm{I}^{2} \mathrm{C}$ Master and Slave Support External Oscillator: up to $40 \mathrm{MHz}$ Internal Oscillator: $8 \mathrm{MHz}$.

Ultrasonic Sensor (HCSR04): We use ultrasonic sensors in robotics when we want to detect obstacles in extreme conditions since the sensor is not affected by dust, moisture, and dirt. Also, an ultrasonic sensor can be used in a dark environment since the light does not affect an ultrasonic sensor's detection ability. In robotics, the ultrasonic sensors are used in applications such as: Object detection, Detect the position of an object, Tracking an object, The distance measured: between 2 and 400 centimeters; Input: Trigger Signal 10us TTL pulse; Output: Echo Signal Output TTL level signal, proportional with range; Update rate: $40 \mathrm{KHz}$; Measuring Angle: 15 degree; Ranging Accuracy: 3mm Power supply: $5 \mathrm{~V}$ with a peak current of $15 \mathrm{~mA}$.

Lead Acid Battery: 12V 1.3Ah sealed lead acid battery, High quality and reliability maintenance free Long life cycle, 12V 1.3Ah sealed lead acid battery. General Features: Sealed and maintenance free operation. Non-Spillable construction design. Safety valve installation for explosion proof. High quality and high reliability. Exceptional deep discharge recovery performance. Low self discharge characteristic. Flexibility design for multiple install positions.
L293D: The Device is a monolithic integrated high voltage, high current four channel driver designed to accept standard DTL or TTL logic levels and drive inductive loads (such as relays solenoides, DC and stepping motors) and switching power transistors.

DC motor: A DC motor is an electric motor that runs on direct current (DC) electricity. The DC motors work in a specified range of the voltage and higher is the input voltage, higher is the RPM. For Example, if the motor works in the range of $6-12 \mathrm{~V}$, it has the least RPM at the input voltage of $6 \mathrm{~V}$ and the maximum RPM at the input voltage of $12 \mathrm{~V}$. The torque and RPM of a geared DC motor depend upon the gear ratio. For example, suppose a DC motor may run at the speed of $12000 \mathrm{RPM}$ and provide $12 \mathrm{~kg}-\mathrm{cm}$ torque. By adding a 255:1 gear down, the speed of the motor can be reduced and torque can be increased. So, by adding 255:1 gear down, the resultant RPM is reduced to $53.3(12000 \mathrm{rpm} / 225)$ and torque is increased to $22.5 \mathrm{kgcm}(0.1 \mathrm{x} \mathrm{225)}$. The motor now is able to move significantly more weight at a reasonable speed.

\section{RESULTS AND DISCRIPTIONS}

Apart from the existing technique, we are proposing an additional advantage by destructing the fire using IR sensor. Operating in real time, infrared detectors pick up movement making them useful in a variety of circumstances, including their use by many fire departments allowing fire fighters, to see through smoke. Infrared detectors are commonly used in the construction of skyscrapers and large structures to detect leaks in pipes.

\section{CONCLUSION}

This project shows the fire fighter robot in which humans have tried to replace human work with new robotics technologies. After considering all of the hardware, software and required mechanical aspect for project we successfully implemented for "FIRE-FIGHTING ROBOT". In this project, we used temperature sensors and gas sensor in automatic mode and perform operation according to sensors detected temperature and gas and extinguishes the fire.

\section{REFERENCES}

[1] Saravanan "Design and Development of Integrated Semi - Autonomous Fire Fighting Mobile Robot.

[2] Kristi Kosasih, E. Merry Sartika, M. Jimmy Hasugian, danMuliady, "The Intelligent Fire Fighting Tank Robot", Electrical Engineering Journal October 2010.

[3] Pic Based Fire Sensing And Extinguishing Robot, Rohith Punuganti, Anusha Srinivas, Lakshmi F 
ISSN (online): 2581-3048

Volume 5, Issue 5, pp 95-97, May-2021 https://doi.org/10.47001/IRJIET/2021.505017

Savanoor, Divya Shreer, Department of Telecommunication, BNM Institution of Technology, Bangalore.

[4] K. L. Su, "Automatic Fire Detection System Using Adaptive Fusion Algorithm for Fire Fighting Robot," in Systems, Man and Cybernetics, 2006.

[5] Rolly Firefighter Robot", William Dubel, Hector Gongora, Kevin Bechtold, and Daisy Diaz, Florida International University, Miami, 2003.

[6] "Engineering criteria 2000," in Engineering Accreditation Commission of the Accreditation Board for Engineering and Technology (ABET), 3rd ed., 2000.

[7] I.Verner and S. Waks, "Educational features of robot contests: The RoboCup'98 survey," Advanced Robotics, vol. 14, no. 1, pp. 65-74, 2000.

[8] R. Murphy, "Competing for a robotics education," IEEE Robot. Automat. Magazine, vol. 8, pp. 44-55, June.

\section{AUTHOR'S BIOGRAPHY}

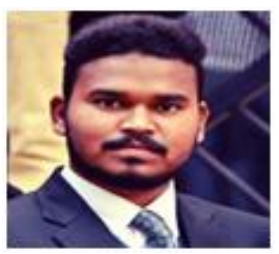

Pratik kumbhar, Student, B.E. Electronics \& Telecommunication Engineering, All India Shri Shivaji Memorial Society Institute of Information Technology, Pune, Maharashtra, India.

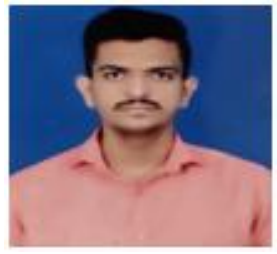

Chaitanya Kharche, Student, B.E. Electronics \& Telecommunication Engineering, All India Shri Shivaji Memorial Society Institute of Information Technology, Pune, Maharashtra, India.

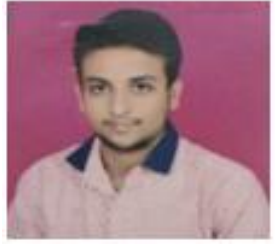

Vaibhav Lonari, Student, B.E. Electronics $\&$ Telecommunication Engineering, All India Shri Shivaji Memorial Society Institute of Information Technology, Pune, Maharashtra, India.

\section{Citation of this Article:}

Devendra Itole, Pratik Kumbhar, Chaitanya Kharche, Vaibhav Lonari, "Fire Fighting Robot" Published in International Research Journal of Innovations in Engineering and Technology - IRJIET, Volume 5, Issue 5, pp 95-97, May 2021. Article DOI https://doi.org/10.47001/IRJIET/2021.505017 